\title{
Analysis of Optimal Harvest and Management of Capture Fishery of Lake Ziway, Central Ethiopia
}

\author{
Kindineh Sisay $^{1 *} \quad$ Greg Hertzler ${ }^{2}$ \\ 1.Haramaya University, School of Agricultural Economics and Agribusiness, PO box 138, Dire Dawa, Ethiopia \\ 2.University of Pretoria, Hatfield Campus, Pretoria 0002, Republic of South Africa
}

\begin{abstract}
Even if there is fluctuation in fish species diversity and relative abundance of the species, Lake Ziway provides numerous environmental and/or ecosystem services. Despite to its importance, the Lake faces numerous threats because of its public good characteristics. Following the exponentially increased demand for fishes and the resource being public good, magnificent number of individuals are participated in capture fisheries in order to secure their livelihood. Free access to the fisheries, illegal fishing gears and environmental degradation are among the main reasons of decline in fish species and degradation of the Lake. From the current stock assessment survey, the study showed decline in biomass of fish over time. These negative trends in the Lake Ziway fisheries and poor water quality led to loss of livelihoods of many households who are directly or indirectly dependent on the Lake. Therefore, management of Lake Ziway fishery becomes very essential to manage the resource efficiently in a way that maximize fishers present and future benefits otherwise, the fish resource will disappear in the near future. Concerning management practices, most of the fishery regulations in this Lake put emphasis on the restriction of fishing gear, but the application of this instrument with its restrictions is almost zero. Moreover, Individual Transferable Quotas (ITQs) foster greater transparency and accountability for the management and enhancement of fishery resources by quota owners. In this regard, since it generates a sense of ownership and its versatility in providing a stable and productive market, ITQs are more effective than gear restrictions and in fact, it has major social benefits by controlling overharvesting. Due to this, to ensure the nutritional and food security of the country currently and in the near future, there is a need to enforce fishing gear restriction and set ITQs. Furthermore, there must be strong effort on studying the current stock of fish, and numbers of legal and illegal fishers to set Individual Transferable Quotas (ITQs) and Total Allowable Catch (TAC) for sustainable fishery management of Lake Ziway. Keywords: Ziway, capture fisheries, Individual Transferable Quotas, Total Allowable Catch, sustainable fishery management
\end{abstract}

DOI: $10.7176 / \mathrm{JESD} / 13-2-03$

Publication date: January $31^{\text {st }} 2022$

\section{Introduction}

Fish is an aquatic species that serves millions of people in the world as a source of food, nutrition, income and livelihood (Fantahun, 2019). Since the ancient civilizations of Egypt and China, fish farming has developed quickly in the animal-based food production field (Olaoye et al., 2013; Tilahun et al., 2016). Currently, in both developed and developing countries, it is practiced (Miller, 2009). The livelihoods of more than 500 million people in developing countries are directly or indirectly linked to fish farming (Brander, 2010). Fish production, processing and marketing activities in Africa help more than 10 million people's livelihoods (Olaoye et al., 2013).

There are large freshwater bodies in Ethiopia with a capacity of 51,500 tons of fish per year (Agumassie, 2018). In the country, there are 180 different fish species and 30 of those are native to the region. Over the last decade, Ethiopia's annual fish production has ranged from 13,000 to 29,000 MT per year (FAO, 2014). More significantly, catches from capturing fisheries serve as a replacement for costly beef and, as a means of affordable nutrition and revenue, play a significant role in domestic consumption. In addition, for poor, landless and unemployed people, the task of fishing in Ethiopia is more important than for the rich (Erkie et al , 2016; Erkie, 2017). Despite this, some fish stocks (Nile perch \& Tilapia) on some Lakes show signs of over-fishing and Lake Ziway's Tilapia is likely at full exploitation (Assefa, 2014). Moreover, over the last three years the fish industry in the country has been in decline due to overfishing, the dumping of hazardous chemicals, pollution in Lakes and rivers, and water hyacinth infestation (Temesgen, 2019).

With respect to fishery management, Ethiopia has no laws yet hence fishery is open access, and there is high localized overfishing. For example, Nile Perch in Lake Chamo and Nile tilapia in Lake Hawassa and Zeway have a problem of overfishing. The main objective of fishery management policy is to curb prevailing over-fishing and recover depleted stocks, ensure conservation of biodiversity and aquatic environment, encourage effective technological advancement, ensure sustainable supply of good fish and improve and secure employment and income for fishery communities (Assefa, 2014). Development of small-scale integrated aquaculture in the country receives high priority in addressing food security and it becomes a prominent element in water harvesting and agricultural development programs. Now a day demand for fishing is increasing and their effective management is urgently required by encouraging capture fishery and aquaculture to sustain the fish resources to meet the 
demand for fish and fishery products (Agumassie, 2018).

Lake Ziway is found to be the most exploited Lake for fishery, irrigation, recreation and tourism, the fishery sustainability of which is reported under threat because of the overfishing activity resulting from an increasing number of fishers residing around the Lake. Besides to its free access to all, regulations related to gear restriction (fishing net and mesh size), quota of harvest and destructive way of fishing are loosely or almost not regulated. The resource in Lake Ziway is currently in an undesirable state due to the large number of anglers and equipment involved and the use of small mesh sizes that catch juveniles and breeding stocks. Its fish resource is declining due to exploitation and will face disappearance if possible measures are not undertaken.

Since direct resource users of the Lake are motivated and willing to share management responsibility (Janko and Zemedu, 2015; Desta, 2018), it is needed to undertake further research to manage this resource thereby to maintain its sustainability. This is to say, despite the usage of the current regulatory tools in Lake Ziway, average size of the catch and Catch per unit effort showed a declining trend and hence, fishers and all the other agents near Ziway are willing to give more focus for this resource management. This could imply that the management practices that are implemented either lack enforcement, are ineffective or inappropriate hence, all users of the Lake are looking either towards other alternative management practices or new updated policy implications that can be perfectly implemented and/or enforceable to sustain the resource for the future. Hence, for addressing the problem of food security and poverty in the country, there is a need to give more focus for fishery management of Lake Ziway. Having these problems, this study is initiated to analyze the present situation of the Lake Ziway and comeup with updated information that would help policy makers/government to further investigate and manage the Lake fisheries.

\section{Materials and Methods}

\subsection{Study Area}

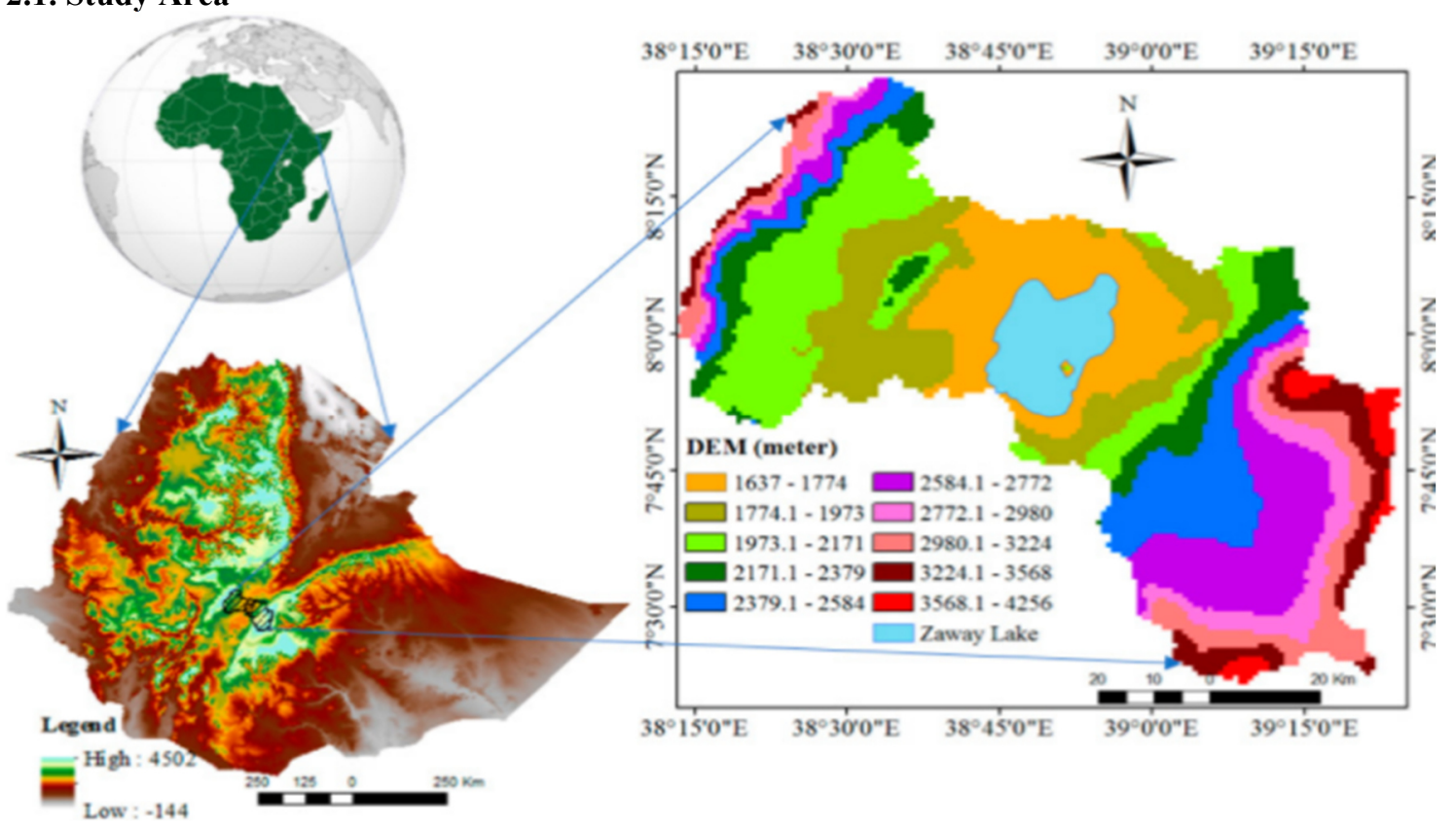

Figure 1. Map of the Study Area.

Source: Own Arc GIS mapping, (2020)

\subsection{Data Types and Sources}

For obtaining primary data, key informant interview and focus group discussion where used while, for the secondary data, hypothetical data of Lake Ziway fishery and different published sources were used.

\subsection{Simulation of an Open Access Fishery}

Lake Ziway is open access and fulfills characteristics of impure public good, which is non-excludable and rival. This is because, no one excludes others from capturing fish and the amount captured by one angler reduces the amount available for others. Hence, the simulation model should be used in all Ethiopian Lakes including Lake Ziway. The model uses the level of harvests without optimizing. Therefore, the producers have no control over biomass because it is determined by decision of the previous seasons. Producers maximize profits, given available biomass at the beginning of that particular season. Then the model is specified as a sequence of profit maximizing. 
Subject to:

$$
\pi\left(\beta_{0}\right)=\max _{0} \int_{0}^{H_{0}} P_{h}(q) d q-P_{e} E\left(H_{0}, \beta_{0}\right)
$$

$$
\beta_{0}=\bar{\beta}
$$

Subject to:

$$
\pi\left(\beta_{1}\right)=\max H_{1} \int_{0}^{H_{1}} P_{h}(q) d q-P_{e} E\left(H_{1}, \beta_{1}\right)
$$

$$
\begin{aligned}
& \beta_{1}-\beta_{0}=G\left(\beta_{0}\right)-H_{0} \\
& \pi\left(\beta_{T-1}\right)=\max H_{T-1} \int_{0}^{H_{T-1}} P_{h}(q) d q-P_{e} E\left(H_{T-1}, \beta_{T-1}\right)
\end{aligned}
$$

Subject to: $\quad \beta_{T-1}-\beta_{T-2}=G\left(\beta_{T-2}\right)-H_{T-2}$

$\pi\left(\beta_{0}\right), \pi\left(\beta_{1}\right) \pi\left(\beta_{T-1}\right.$ are the profits from capturing of fish for respective years, $\beta$ is the biomass or stock of fish, $\mathrm{H}$ is the harvest, $\mathrm{E}$ is the effort function, which depends upon harvest and biomass, $\mathrm{G}$ is a growth function, which depends on the biomass, $\mathrm{Ph}$ is price for fish in the market and $\mathrm{t}$ is time measured as fishing seasons. The biomass begins at an initial biomass and evolves over time depending upon growth and harvest.

Unlike optimally managed fishery, open access fishery has no marginal user costs, which are the price of biomass. Therefore, the first-order condition for open access will be:

$$
\begin{gathered}
\frac{\partial \pi}{\partial \mathrm{Ht}}=\mathrm{Ph}(\mathrm{Ht})-\mathrm{Pe} \frac{\partial E(H t, \beta t)}{\partial H t}=0 ; t=0, \ldots \ldots T-1 \\
\mathrm{Ph}(\mathrm{Ht})=\operatorname{Pe} \frac{\partial E(H t, \beta t)}{\partial H t}
\end{gathered}
$$

In the above equation, biomass still changes and fishery may be overexploited. Being non-excludable, there is no incentive to harvest less today and conserve more for feature, because if one producer tries to conserve for the future, some other producer will catch the fish instead. However, this is not always, either fishery reaches a steady state or crashes, because all producers will profitably catch today. This will leave some fish for the next season, but less than the optimal amount. In the next season, producers will again harvest all they can profitably catch, leaving fewer fish for subsequent seasons, and reaches a steady state or crashes.

Even so, the fishery may reach the steady state in which the biomass and harvest changing and fishery is managed sustainably, if not optimally. So, the steady state for open access becomes

$$
\begin{aligned}
& \mathrm{Ph}(\mathrm{Ht})=\mathrm{Pe} \frac{\partial E(H t, \beta t)}{\partial H t} \\
& \mathrm{H}_{\infty}=\mathrm{G}\left(\mathrm{B}_{\infty}\right)
\end{aligned}
$$

Where the first equation is all possible profit-maximizing steady states and the second equation defines all possible biological steady states. If these equations can be solved simultaneously, there is an open access steady state. Indeed, there may be two open-access steady states.

\subsubsection{Simulation of Current Policy of Gear Restrictions}

The main policy of gear restrictions includes limits on fishing technologies, such as the mesh size. This restriction increases the cost of fishing and reduces harvest but does not halts the problem of open access. This is due to producers maximize short-run profits and often substitute other technologies such as more powerful boats.

$$
\begin{array}{r}
\pi\left(\beta_{T-1}\right)=\max H_{T-1} \int_{0}^{H_{T-1}} P_{h}(q) d q-P_{e} E\left(H_{T-1}, \beta_{T-1}\right) \\
\text { Subject to: } \quad \beta_{T-1}-\beta_{T-2}=G\left(\beta_{T-2}\right)^{-}-H_{T-2}
\end{array}
$$

\subsection{Model of Optimally Managed Fishery}

Unlike open access, this model requires price for biomass, which is called as marginal user cost. In this model, there is an owner who collects rent which is collected by protecting and conserving the fishery. The fishery model with an infinite time horizon is far too large to solve, as a result, the model should be divided into two transition phases and optimal steady state. By assuming fishery converges to optimal steady-state before time $\mathrm{T}$, the model for optimal management becomes

$$
N P V\left(\beta_{0}\right)=\max _{H_{t}} \sum_{t=0}^{T-1}\left(\frac{1}{1+r}\right)^{t}\left[\int_{0}^{H_{t}} P_{h}(q) d q-P_{e} E\left(H_{t}, \beta_{t}\right)\right]+N P V\left(T, \beta_{T}\right)
$$

Subject to:

$$
\begin{gathered}
\beta_{0}=\bar{\beta} \\
\beta_{t+1}-\beta_{t}=G\left(\beta_{t}\right)-H_{t} ; t=0, \ldots . T-1
\end{gathered}
$$


Where,

$$
\begin{gathered}
N P V\left(T, \beta_{T}\right)=\frac{\left(\frac{1}{1+r}\right)^{t}}{r}\left[\int_{0}^{H_{T}} P_{h}(q) d q-P_{e} E\left(H_{T}, \beta_{T}\right)\right] \\
\text { Subject to: } \quad H_{T}=G\left(\beta_{t}\right)
\end{gathered}
$$

With biomass and harvest constant, the net present value can be calculated using an annuity formula

$$
\operatorname{NPV}\left(T, \beta_{T}\right)=\frac{\left(\frac{1}{1+r}\right)^{T-1}}{r}\left[\int_{0}^{H_{T}} P_{h}(q) d q-P_{e} E\left(H_{T}, \beta_{T}\right)\right]
$$

Subject to:

$$
H_{T}=G\left(\beta_{t}\right)
$$

NPV is the net present value of benefits above costs from the fishery, $\beta$ is the biomass or stock of fish, $H$ is the harvest, $\mathrm{E}$ is the effort function, which depends upon harvest and biomass, $\mathrm{G}$ is a growth function, which depends on the biomass, $\mathrm{Ph}$ is price for fish in the market and $\mathrm{t}$ is time measured as fishing seasons. The biomass begins at an initial biomass and evolves over time depending upon growth and harvest. In order to show the results of optimum management from the above model. By constructing Undiscounted Hamiltonian, we can describe the welfare of society from fishery optimum management as follows

$$
\mathcal{H}\left(H_{t}, \beta_{t}, \psi_{t+1}\right)=\left[\int_{0}^{H_{t}} P_{h}(q) d q-P_{e} E\left(H_{t}, \beta_{t}\right)\right]+\psi_{t+1}\left[G\left(\beta_{t}\right)-H_{t}\right]
$$

First Order condition for Undiscounted Hamiltonian:

$$
\begin{gathered}
\frac{\partial \mathcal{H}\left(H_{t}, \beta_{t}, \psi_{t+1}\right)}{\partial H_{t}}=0=P_{h}\left(H_{t}\right)-P_{e} \frac{\partial E\left(H_{t}, \beta_{t}\right)}{\partial H_{t}}-\psi_{t+1} ; t=0, \ldots, T-1 \\
-\frac{\partial \mathcal{H}\left(H_{t}, \beta_{t}, \psi_{t+1}\right)}{\partial \beta_{t}}=P_{e} \frac{\partial E\left(H_{t}, \beta_{t}\right)}{\partial \beta_{t}}-\psi_{t+1} \frac{\partial G\left(\beta_{t}\right)}{\partial \beta_{t}}=\psi_{t+1}-(1+r) \psi_{t} ; t=0, \ldots, T-1 \\
\frac{\partial \mathcal{H}\left(H_{t}, \beta_{t}, \psi_{t+1}\right)}{\partial \psi_{t+1}}=\beta_{t+1}-\beta_{t}=G\left(\beta_{t}\right)-H_{t} ; t=0, \ldots, T-1
\end{gathered}
$$

The first equation in the above FOC equates the market price of fish with marginal effort cost and marginal user cost. The second one equates marginal profit from fish production with the change in its marginal user cost and the final shows change in biomass, which equates extraction of fish with a decrease in biomass of fish.

\section{Result and Discussion}

\subsection{Evaluation of the Effectiveness of gear restriction}

Gear restrictions are preserving biomass above key threshold levels for sustainable fisheries but are not achieving conservation targets. Even with gear restrictions, the preferred target species are still being exploited. Unregulated fishery and open access principles of the Lake are the main causes of overfishing in Ethiopia (Pattnaik, 2014). Open access destroys the rent because producers behave as if the price of biomass is zero and maximize short-run profits. The main biological policy of fishery is gear restriction, which limits fishing technologies, such as size of the net.

In Ethiopia fishery conservation measures includes restriction of mobility of live fish, prohibition of destructive gear (which are totally banned), mesh regulation, area or seasonal regulation, declaring a reserve in a park, allocation of catch, territorial right, and economic measures including increasing tax on license and reducing subsidies for gear (FDRE, 2003). In Lake Ziway, this gear restriction policy reduced the mesh size from $10 \mathrm{~cm}$ to $8 \mathrm{~cm}$. The number of anglers, the average number of nets used daily on the Lake, mesh size and number of nets owned by each angler are decreased after gear restriction policy (Yosef et al, 2017). Indeed, gear restriction increase the cost of fishing and reduce harvest but do not address the problem of open access. This is due to the reason that producers can maximize short-run profits and often substitute other technologies, such as more powerful boats.

\subsection{Evaluation of Effectiveness of ITQs}

Recently fishery economists have managed some capture fisheries mostly by using policy of choice, which is individual transferable quotas (ITQ), which addresses the problem of open access by creating owner of the quota who becomes the owner of the fishery. Owners can be individuals or governments, but those owners must ensure that their quotas are enforced and properly priced. Indeed, the price of quota is also the missing market price of the biomass. By creating a market for quotas, the fishery can be managed optimally and sustainably for present and future generations (For more, look the graph bellow obtained using hypothetical data).

\subsubsection{Implementation Plan for Optimal Management}

Table below shows ten-year plan for optimal fishery management assuming higher demand. It includes optimal 
harvest level and marginal user cost, which is the price of biomass swimming in the Lake. Therefore, it is taken as price of ITQ and government share ownership for producers or compensate them by using direct payment. When this happens, Pareto improvement is possible and ITQ policy is effective (This can be clearly shown from the following table and graph obtained using hypothetical data).

\begin{tabular}{lll}
\hline Year & Optimal harvest (TAC) & MUC $_{\mathrm{t}+1}$ (Price of ITQ) \\
\hline 2020 & 6.55 & 25.43 \\
2021 & 7.15 & 23.44 \\
2022 & 7.69 & 21.70 \\
2023 & 8.16 & 20.22 \\
2024 & 8.59 & 18.91 \\
2025 & 8.97 & 17.77 \\
2026 & 9.31 & 16.77 \\
2027 & 9.62 & 15.89 \\
2028 & 9.89 & 15.13 \\
2029 & 10.13 & 14.46 \\
2030 & 10.34 & 13.86 \\
\hline
\end{tabular}

Table 1. Model Result by using hypothetical data of the Lake.

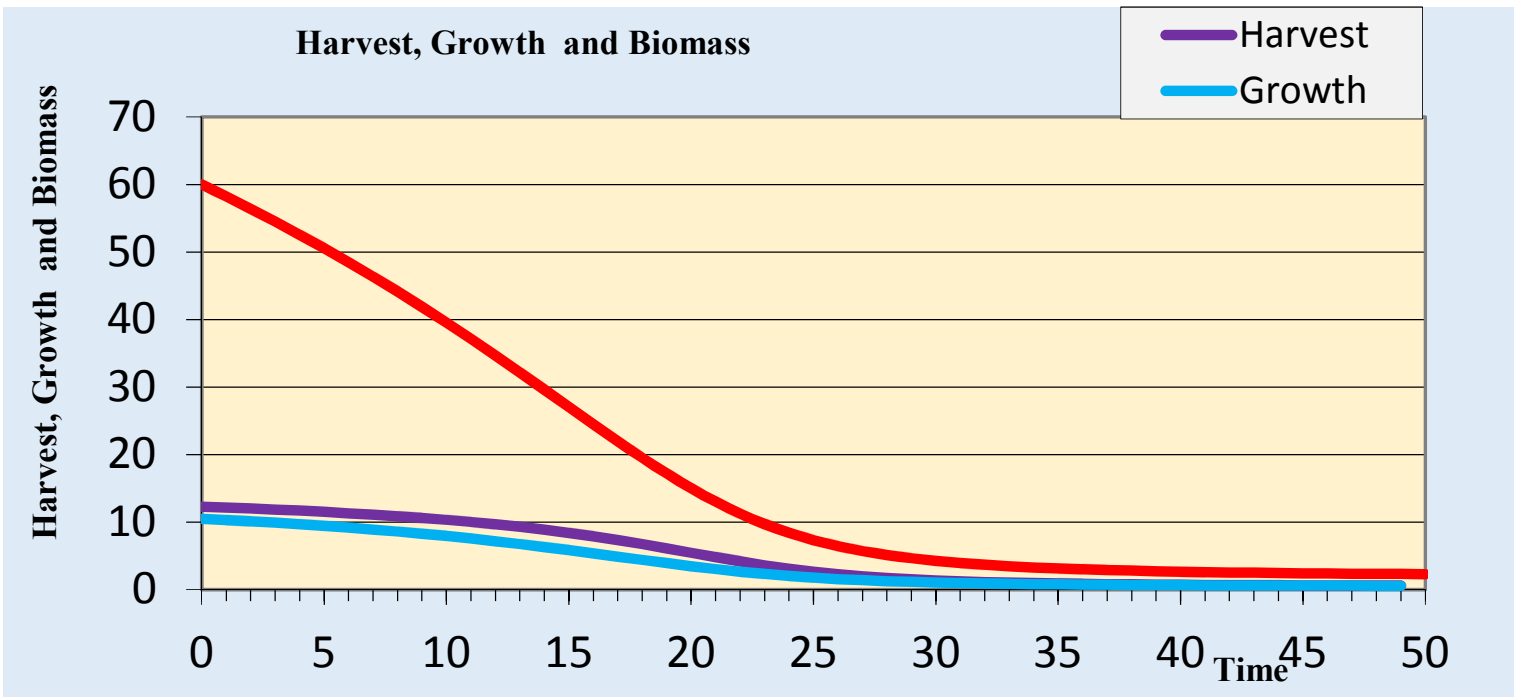

Figure 2. Open access - which shows a decrease in biomass due to lack of policy.

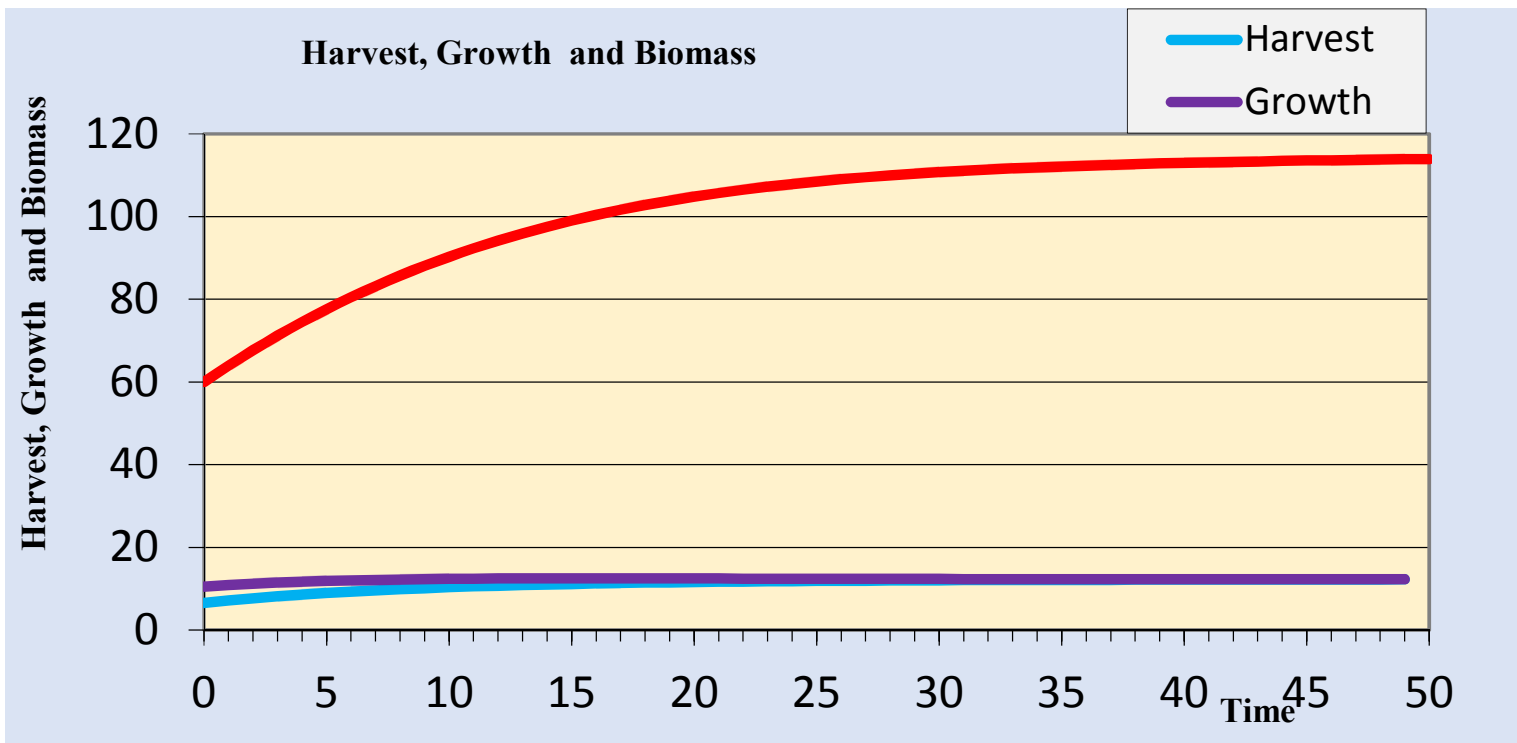

Figure 3. Optimal management - which shows an increase in biomass due to the existence of policy (e.g. ITQ policy)

Fig 2 and 3. Model Result by using hypothetical biomass, harvest, effort, etc. data of Lake Ziway. 


\subsubsection{Pareto Improvement Mechanisms of Welfare Compensation}

This compensation would be focused on the demand for fish from customers. Producers prefer higher demand, even though open access fisheries are even crashing. Even if fishing does not fail, customers prefer intermediate demand. Producers prefer open access to good intermediate and low demand. Consumers desire optimum management of elevated demand. Consumers prefer open access, with intermediate and low demand. Owners and society as a whole prefer optimum control at all times.

Optimal management is potentially a Pareto improvement. Unfortunately, open access may be favored by producers and customers and they may oppose a strategy of introducing an optimal solution. Owners should pay producers and customers in order to minimize resistance. Potential benefits to society are the net present value, not counting the cost of designing and implementing a policy. With high demand, owners can pay producers easily. The compensation could be a direct payment or a share in the fishery's possession. There is a higher demand at Lake Ziway at present, due to the reason that the Lake is located in a regional city and even taken as a tourist spot, which have a long-term fishing experience. The strategy would handle fisheries optimally by compensating farmers for the rent received, assuming higher demand. Therefore, implementation of ITQ policy is very important in order to ensure fish sustainability. The government may compensate the producers because with higher demand they become affected. Compensation will be based on direct payment for producers or sharing of ownership of fishery. (For more, look the graph obtained using hypothetical data)

\subsection{Discussion}

As effort expended on fish stock increases, a continuous increase in capture per unit of effort could not be realized in production. If their natural growth is exceeded by the harvest, the stock will decrease. While they are a sustainable natural resource, all removals that surpass their capacity to replicate and grow, cannot be maintained. Their capacity to sustain will decline as long as they are under greater harvest pressure than their capacity to replenish. Their biological dynamics limit them to the indefinite preservation of the harvest. Harvests that are relatively large for the capacity of the fish stock to sustain overtime have been a challenge to overfishing in recent years (Hartwick and Olewiler 1998). If effort on a specific stock continues to increase the harvest, their growth can be surpassed. This means that the stock will gradually decrease as it loses its viability at a high level of effort and fish stocks are not infinite. A continuous growth in effort can lead to an increase in catch, but proportionately smaller harvests can result in a decreasing rate or more effort, i.e. the additional effort would have less return. The well-known economic theory of decreasing marginal product of a variable factor (Hartwick \& Olewiler 1998) also indicates that, given a specific fish stock, the marginal product of effort slopes downwards. It is understood that an open access equilibrium is economically unsustainable because the economic rent that fisheries would have gained here would have been lost. Each resource user may not recognize open for all resource use, or each user may disregard the stock effect. An open access balance, therefore, would require more effort than is socially optimal. Open access equilibrium would lead to the introduction by the individual user of additional costs on all users, which would increase the cost of harvesting.

\subsection{Key for Management Implications}

Fisheries in Lake Ziway are controlled by technical and production control mechanisms, which appear to be lacking proper control or enforcement, most likely because of their high cost. These laws fall within the scope of fishing associations. Based on the preliminary results of this report, these management tools have identified a biologically efficient and economically inefficient status for fisheries.

While managed by conventional management steps, the Lake can be said to be under open access, leading each fisher to obtain the average result of the total effort of the association. The total harvest divided by the total effort will decide the yield per fishery. Each fisher does not capture the marginal result of his / her effort. The fisher rather harvests the associations' average product, which will lie above marginal product. This is because of the new entry of effort to share the resource rent earned from the fishery, even though the increase in output obtained by adding one unit of fisher (marginal product) decreases. The total product may increase as the number of fishers' increases but at a decreasing rate, since they are dealing with finite creatures. Ultimately, the stock might dwindle and increase the cost of harvesting. Harvesting a given quantity with a lower stock could require more effort than with a higher stock. In both ways, the best way to manage the fishery might be to adopt the precautionary approach, which focuses on the integration of social, economic and biological objectives during management planning. It also refers the usefulness of defining safe biological limits with low fishing mortality and high spawning stock biomass. Implementation that puts in place all planned decisions needs also to involve the interested parties.

Some of these precautionary approaches could occur in the Lake with low enforcement ability, according to the current management situation of the Lake, which could be a major issue in the sustainable management of the Lake. Whatever attempt to enforce the existing regulations is made according to LFDP (1996), enforcing only is not sufficient. The use of illegal fishing gears and change in the size of gears is widespread. Whatever be the 
ultimate management tools decided upon, the question of control would be central to any success or failure. It could either by the anglers themselves and/or authority based approach to management. The easiest way, according to LFDP (1996), to implement the management tools is control by the anglers themselves. As Neiland (1997) also pointed, overexploitation of fisheries increased through time as a result of a limited success of centrally controlled fishery management systems and many fisheries under "common property resource" have been managed effectively in the past by local community-based fisheries management institutions that have been ignored by centrally- controlled management systems.

\section{Conclusions and Recommendations}

Even though contribution of fisheries from Lake Ziway is extremely large for both smallholders and commercial anglers, lack of property rights and loosening of regulation endangers the fishery resource. In addition, the essence of the resource's non-exclusiveness and rivalry exacerbates competitiveness and the illicit way of fishing. Most of the fishery regulations in this Lake put emphasis on the restriction of fishing gear, but the application of this instrument with its restrictions is almost zero. Moreover, ITQs foster greater transparency and accountability for the management and enhancement of fishery resources by quota owners. In this regard, since it generates a sense of ownership and its versatility in providing a stable and productive market, ITQs is more effective than gear restrictions and in fact, it has major social benefits by controlling overharvesting. Due to this, the following points were recommended to sustain fishery production of the country there by to ensure the nutritional and food security of the country. The first and most important thing is enforcing fishing gear restriction. This allows the fishery resource to regenerate itself by avoiding illegal and destructive way of fishing. Despite to this, only gear restriction such as control in mesh size is not fully overcoming the problem of over-fishing indeed the policymaker should focus on ITQ and TAC in order to manage this fish resource optimally thereby to attain food security of the country. However, at the time of researching, the total stock of fish in Lake Ziway fishery is not well known, fishers have no license and fish with small mesh sized and illegal gillnet. Under these conditions, application of ITQ is difficult to set total allowable catch (TAC). Due to this, for the time being, gear restriction is more compatible for the study area even if ITQ is the most efficient method. Therefore, there must be strong effort on studying the current stock of fish, numbers of legal and illegal fishers to set Individual Transferable Quotas (ITQ) and Total Allowable Catch (TAC) as a Lake Ziway fishery management. In order to sustain optimal management policy, the government should employ Pareto improvement mechanisms of welfare compensation based on the demand for fish this can be done by restricting the number of fishers and harvest at each year to the optimal level. Mostly fish resources in Ethiopia, especially in Ziway, are managed by biological policy therefore, incorporating environmental economists' decision in optimal management is important. Now a day, the quality of Lake Ziway is deteriorating due to ineffective management of its watershed and overfishing, so in order to ensure fish resource sustainability, emphasis should be given to integrated watershed management practices. In addition to those, strong enforcement on the type of gear to be used and fishing license should have to be employed or applied, which can serve as a means of exclusion and closing season for regeneration. Moreover, the catch quota of commercial anglers and other methods of internalizing the externality of wealthy and selfish anglers should have to be used. To sum up, currently, Ethiopian government is implementing integrated aquaculture in small-scale agriculture to ensure food security by taking productive fish varieties from regulative open access, therefore effective optimal policy of fishery is important to conserve fish stock.

\section{Acknowledgement}

The authors gratefully acknowledge the contribution of fishers, district officials and all other concerned bodies who made tremendous efforts to make the research successful (by engaging in the Focus Group Discussion (FGD) and providing information during Key Informant Interview (KII)).

Ethical approval

We are agreed to submit the manuscript by being responsible for its content.

Consent for publication

We are agreed to publish our manuscript under this journal.

Availability of data and materials

The data that support the findings of this study are available from the corresponding author upon reasonable request. Competing interest

We declare that we the authors have no competing interests.

Funding

Any financing institutions did not financially support this work.

Authors' contributions

The author read and approved the final manuscript.

Author's information

Kindineh Sisay is Lecturer at Haramaya University in school of Agricultural economics and agribusiness. Prof 
Greg Hertzler is Extra Ordinary Professor at University of Pretoria, Hatfield Campus, Pretoria 0002, Republic of South Africa.

\section{References}

Agumassie T. (2018). Review in current problems of Ethiopian fishery: in case of human and natural associated impacts on water bodies. International Journal of Fisheries and Aquatic Studies 6(2): 94-99.

Assefa, M.J. (2014). Research Article Open Access Fish Production, Consumption, and Management in Ethiopia.

Birhanu, W. (2015). Determinants of Fish Production in Lake Ziway, Ethiopia (Doctoral dissertation, St. Mary's University).

Brander, K. (2010). Impacts of climate change on fisheries. Journal of Marine Systems, 79, 389-402. doi:10.1016/j.jmarsys.2008.12.015.

Conrad, John M., Resource Economics, $2^{\text {nd }}$ edition, Cambridge university press, 2010, Chapter 3.

Desta, Y. (2018). Analysis of Economic Value of Lake Ziway: An Application of Contingent Valuation Method. Journal of Resources Development and Management, 40.

Erkie A. (2017). Current trend of water hyacinth expansion and its consequence on the fisheries around northeastern part of Lake Tana, Ethiopia. Journal of Biodiversity \& Endangered 5(2): 2-5.

Erkie A, Sewmehon D, Dereje T. (2016). Fisheries of Jemma and Wonchit rivers: as a means of livelihood diversification and its challenges in north Shewa zone, Ethiopia. Fisheries and Aquaculture Journal 7(4): 17.

Fantahun, T. (2019). Assessment of the fishery, challenges and opportunities of Denbi reservoir in Bench Maji Zone, South Western part of Ethiopia. International Journal of Fisheries and Aquaculture, 11(1), pp.7-12.

FAO (2014). Fisheries in ESA-IO region profile and trends Country review: Ethiopia

FDRE (2003). Information on the fishery management in the Federal Democratic Republic of Ethiopia.

Garoma, D., Admassie, A., Ayele, G. and Beyene, F. (2013). Analysis of determinants of gross margin income generated through fishing activity to rural households around Lake Ziway and Langano in Ethiopia. Agricultural Sciences, 4(11), p.595.

Hailu, E. (2017). Socioeconomic and institutional factors determining the utilization of fish resource in Lake Ziway. Journal of Fisheries and Aquaculture Development.

Hartwick, J.M. and Olewiler, N.D. (1998). The Economics of Natural Resource Use, nd Addison-Wesley. Reading, Massachusetts.

Janko, A.M. and Zemedu, L. (2015). Fisher Man's Willingness to Pay for Fisheries Management: The Case of Lake Zeway, Ethiopia. Journal of FisheriesSciences. Com, 9(4), pp.016-022.

LFDP. (1996). Proceedings of the National Fisheries Seminar, Ziway. November 1995. Lake Fisheries Development Project Working Paper no. 21 Addis Ababa. Ministry of Agriculture.

Miller, J. W. (2009). Farm pond for water, fish and livelihood. Retrived from http://www.fao.org/3/ i0528e/i0528e.pdf.

Neiland, A.E. (ed.). (1997). The Traditional Management of Artisanal Fisheries in N.E. Nigeria: Final Report. ODA Project No. 5471. CEMARE Report. University of Portsmouth, UK.

Olaoye, O., Ashley-Dejo, S., Fakoya, E., Ikeweinwe, N., Alegbeleye, W., Ashaolu, F., \& Adelaja, O. (2013). Assessment of socio-economic analysis of fish farming in Oyo State, Nigeria. Global Journal of Science Frontier Research Agriculture and Veterinary, 13, 45-55.

Pattniak, B.S. (2014). Impact of overfishing on ecology of Lake Hawassa at Amora Gedel, Ethiopia

Perman. R, Ma. Y, McGilvary. J and Common. M. (2003). Natural Resource and Environmental Economics. Third Edition

Temesgen. M. (2019). Ethiopia: Fasting Season, No Longer Boon for Fish Industry

Tilahun, A., Alambo, A., \& Getachew, A. (2016). Fish production constraints in Ethiopia: A review. World Journal of Fish and Marine Sciences, 8, 158-163.

Yosef. T/G, Alemken. B, Elias. D. (2017). Assessment of Sustainable Yield and Optimum Fishing Effort for the Tilapia (Oreochromis niloticus L. 1758) Stock of Lake Hawassa, Ethiopia 